\title{
Clinical and Radiological Predictors of Recanalization after IV rt-PA in Patients of Acute Ischemic Stroke
}

\author{
MOHAMED M. EL-SHENAWY, M.Sc.*; EL-SAYED A. TAG EL-DIN, M.D.*; AZZA A. GHALI, M.D.* and \\ RASHA L. YOUNES, M.D.** \\ The Departments of Neurology* and Diagnostic Radiology**, Faculty of Medicine, Tanta University
}

\begin{abstract}
Background and Aim: Acute Ischemic Stroke (AIS) is defined as a focal neurological deficit lasting for more than 24 hours with no cause other than that of vascular origin. Stroke is the third commonest cause of mortality after cardiac disease, cancer and the first cause of disability. Current treatment for AIS includes thrombolytic drugs such as rt-PA which dissolve occlusive blood clots and reversing the ischemia in salvageable area of the penumbra adjacent to irreversible infracted area. The purpose of this study is to assess the predictors of recanalization after treatment via rt-PA.
\end{abstract}

Aim of Study: Was to assess the clinical and radiological predictors of the recanalization after IV thrombolytic therapy in patients of AIS.

Subjects and Methods: This study was conducted in the Departments of Neuropsychiatric and Radiology, Tanta University on 25 patients of AIS in the period between August 2016 and February 2017. They were classified into 2 groups according to the successful recanalization or not. All patients were subjected to full history taking, neurologic examination including evaluation by National Institute of Health Stroke Scale (NIHSS), laboratory investigations, neuroimaging including: Computed Tomography (CT), Transcranial Doppler Ultrasound (TCD) and CT angiography which were done with follow-up 24 hours later.

Results: The mean age of the group of successful recanalization was $62.12 \pm 13$ while in the group of failed recanalization was $69.21 \pm 10$. Smoking and DM were significantly higher among patients with failed recanalization while cardiac problems were significantly more common in patients with successful recanalization. In addition, the recanalization was associated with significant improvement in stroke severity. Distal MCA occlusion had a better chance of recanalization via rt-PA than proximal MCA occlusion.TCD had $81.25 \%$ sensitivity and $100 \%$ specificity compared to CTA.

Conclusion: IV rt-PA is an effective treatment of AIS. Earlier rt-PA timing of administration and lower NIHSS were significant predictors for successful recanalization. TCD is an easy, fast and feasible tool to assess the occluded vessels with near results to CTA.

Correspondence to: Dr. Mohamed M. El-Shenawy, The Department of Neurology, Faculty of Medicine, Tanta University
Key Words: Recanalization - Thrombolytic - Stroke.

\section{Introduction}

STROKE is considered one of the important global health problems as 15 million people worldwide suffer a stroke annually; of those, 5 million die and another 5 million are left permanently disabled, placing a burden on family and community [1] .

Currently, recombinant tissue Plasminogen Activator (rtPA) is the only approved drug for acute stroke and shows significant benefits when administered intravenously less than $4.5 \mathrm{~h}$ after stroke [2].

The rationale for thrombolysis for acute ischemic stroke is re-canalization of occluded arteries to reestablish brain function by saving tissue at risk (penumbra). The speed of intracranial clot lysis and recanalization has been shown to be strongly associated with early neurological improvement, reduced infarct size, and favorable prognosis [3] .

After the demonstration of the efficacy of endovascular treatment (intra-arterial tPA and mechanical thrombectomy) for acute ischemic stroke in the recent randomized controlled trials predicting which patients will respond best to thrombolytic therapy remains a challenge, to limit futile, resource-consuming, and saving time to salvage penumbra [4-7].

Aim of the work: Was to assess the clinical and radiological predictors of the recanalization after IV thrombolytic therapy in patients of AIS.

\section{Subjects and Methods}

This study had been conducted on a group of patients with AIS admitted to the stroke unit, Department of Neuropsychiatry, Psychiatry- 
Neurology center, with full radiological evaluation within the Radiology Department Tanta University Hospital. The time frame of this study was 6 months in the period from August 2016 to February 2017.

Inclusion criteria; Sudden focal neurological deficit attributable to AIS, age between $18 \& 80$ years and clearly defined time of onset allowing initiation of rt-PA within time window (4.5 hours).

Exclusion criteria; Age less than 18 or more than 80 years old, severe stroke (NIHSS $>22$ ) or minor stroke (NIHSS <4), rapidly improving neurological deficit or minor symptoms, coma or seizure at the onset of stroke, clinical presentation suggestive of a SAH (even if CT scan was normal) or previous history of or suspected $\mathrm{ICH}$, posterior circulation infarction, serious head trauma or prior stroke within the last 3 months, contraindications to iodinated material as pregnancy and renal failure, severe uncontrolled hypertension defined by a systolic blood pressure $>185 \mathrm{mmHg}$ or diastolic $\geq 110 \mathrm{mmHg}$ in 3 separate occasions at least 10 minutes apart or requiring continuous IV therapy, baseline INR greater than 1.5 , aPTT more than 1.5 times of normal, or baseline platelet count less than 100,000 per cubic millimeter, baseline blood glucose concentrations below $50 \mathrm{mg}$ per deciliter or above $400 \mathrm{mg}$ per deciliter, CT brain showing any degree of hemorrhage or a multilobar infarction (hypodenisty in more than $1 / 3$ of the MCA territory) and significant mass effect with midline shift.

Each patient was subjected to clinical and radiological assessment as following:

1- Full history taking and complete general examination were done to determine the risk factors of stroke.

2- Thorough neurological examination; including assessment of patient's stroke severity according to National Institute of Health Stroke Scale (NIHSS) on admission and 24 hours after the infusion. (NIHSS is a tool used to objectively quantify the impairment caused by a stroke. The NIHSS is composed of 11 items, each of which scores a specific ability between a 0 and 4 . For each item, a score of 0 typically indicates normal function in that specific ability, while a higher score is indicative of some level of impairment. The individual scores from each item are summed in order to calculate a patient's total NIHSS score. The maximum possible score is 42 , with the minimum score being a 0 [8]

3- Radiological evaluation including brain $\mathrm{CT}$ to exclude hemorrhagic stroke and select patients for rt-PA.
4- Transcranial and extracranial ultrasonography was done on admission to determine the occluded vessels and 24 hours after IV rt-PA to detect re-canalization. Standard Extracranial Colorcoded Duplex Sonography (ECCS) was performed to evaluate atherosclerotic lesions. This was done by using linear array transducer of multifrequency (3-12) MHz real time, saggital, coronal and axial views.

\section{5- Middle cerebral artery TCD monitoring:}

A- Unilateral TCD monitoring was also done by phased array transducer of multifrequency (13) $\mathrm{MHz}$, used in transaxial mesencephalic view through the temporal window. Briefly, after optimization of the transmit frequency and power, focal zone, and pulse repetition frequency, the color gain was adjusted for the individual acoustic bone window so that random-color speckling outside the vessel borders could be avoided. The Doppler gate was $5 \mathrm{~mm}$ in all intracranial blood flow measurements. Angle-corrected measurements were performed for the MCA in all cases. The initial TCD examination was performed just before administration of intravenous t-PA. Peak systolic, diastolic and mean flow velocity and pulsatility index were measured.

B- Thrombolysis in Brain Ischemia (TIBI) flow grading system [9] measure the residual flow in MCA after thrombolysis. It consists of 6 grades;

The protocol was as follows: After defining TIBI grade of 3 or less, the sample volume length was set at $10 \mathrm{~mm}$; monitoring started just after administration of intravenous thrombolysis and continued for $2 \mathrm{~h}$. Continuous off-line monitoring of recanalization was performed by an qualified neurosonologist and documentation of TIBI grades made a 5 minutes intervals through the 2 hours monitoring period. Full recanalization was definite as attainment of TIBI grades 4 or more.

6- Brain non contrast CT was performed. The Alberta Stroke Program Early CT (ASCPECT) score for assessment the severity of MCA infarction detected by CT was done (it is a 10point quantitative topographic CT scan score used in patients with middle cerebral artery stroke [10]. Segmental assessment of the MCA vascular territory is made and 1 point is deducted from the initial score of 10 for every region involved.

7- CT angiography 24 hours after rt-PA administration to confirm the recanalization. Imaging was performed on 16-detector CT scanner Toshiba slice thickness $1.5 \mathrm{~mm}$, pitch $1.5: 1$, helical scanning mode, installed at Psychiatry- 
Neurology and Neurosurgery Center with an intravenous bolus of $100 \mathrm{~mL}$ of Iopromide $300 \mathrm{mg}$ contrast media administered via a power injector with flow rate of $4 \mathrm{ml} / \mathrm{sec}$ followed by $30 \mathrm{ml}$ flush of saline. Scanning was timed to permit imaging proximal and distal branches of the circle of Willis.

8- Routine laboratory investigations including random blood sugar, liver functions, renal functions, blood picture and serum electrolytes.

9- Radiological follow-up CT brain for was done 24 hours after the infusion in addition to Transcranial duplex (TCD) and CT angiography to assess recanalization.

10- Clinical follow-up of the studied patients after 24 hours of admission including evaluation of NIHSS.

- The studied patients were divided into two groups:

Group 1: Include 16 patients with successful recanalization (by CTA and TCD) with further subdivision into group (1A); patients with clinical improvement (their age were $62.3 \pm 10.5$ years and $5(45.5 \%)$ of them were male). And group (1B); patients without clinical improvement (their age were $63.9 \pm 10.5$ years and 3 of them were male). There was no significant difference between both subgroups regarding sex nor age.

Group 2: Include 9 patients with failed recanalization (by both CTA and TCD). Their age were $67.0 \pm 12.7$ and $4(44.4 \%)$ of them were male. There was no significant difference between both group I \& II regarding age and sex.

Nine patients with poor insonation window by TCD and two patients with ACA occlusion were excluded from the study.

\section{Statistical analysis:}

The collected data were organized, tabulated and statistically analyzed using SPSS software statistical computer package Version 16. For quantitative data, the range, mean and standard deviation were calculated. For qualitative data, comparison between two groups and more was done using Chisquare test $\left(\chi^{2}\right)$ and Fisher extract test.

\section{Results}

Regarding the risk factors among the studied groups, smoking and DM were significantly higher among patients with failed recanalization ( $p=0.001$ and 0.04 respectively) while cardiac problems were significantly more common in patients with successful recanalization $(p=0.02)$. Regarding the stroke severity measured by (NIHSS), there was no significant difference between both groups on admission but 24 hours after rt-PA administration, the recanalization was associated with significant improvement in stroke severity $(p<0.05)$.

According to the ASPECT score at 24 hours after rt-PA administration, it was significantly lower among patients with failed recanalization than those with successful recanalization (Table 1).

Table (1): ASPECT score by CT scan after 24 hours of rt-PA administration in the studied patients.

\begin{tabular}{|c|c|c|c|}
\hline & \multicolumn{2}{|c|}{ Group $1(n=16)$} & \multirow{2}{*}{$\begin{array}{l}\text { Group } 2 \\
(\mathrm{n}=9)\end{array}$} \\
\hline & $\begin{array}{l}\text { Group 1A } \\
(\mathrm{n}=11)\end{array}$ & $\underset{(\mathrm{n}=5)}{\text { Group } 1 \mathrm{~B}}$ & \\
\hline \multicolumn{4}{|c|}{ ASPECT after 24 hour: } \\
\hline$<7$ cut of point & $10(90.9 \%)$ & $1(20 \%)$ & $2(22.2 \%)$ \\
\hline$>7$ cut of point & $1 \quad(9.1 \%)$ & $4(80 \%)$ & $7(77.8 \%)$ \\
\hline$\chi 2(p$-value $)$ & \multicolumn{2}{|c|}{$5.8(0.024 *)$} & \\
\hline
\end{tabular}

As regarding TIBI score done by TCD among the both studied patients groups It was significantly higher in the patients with successful recanalization (Group I) than those with failed recanalization (Group II) (Table 2).

Table (2): Thrombolysis in brain ischemia (TIBI) scale in the studied patients.

\begin{tabular}{lccc}
\hline & \multicolumn{2}{c}{ Group 1 $(\mathrm{n}=16)$} & \\
\cline { 2 - 3 } $\begin{array}{l}\text { Transcranial } \\
\text { Duplex }\end{array}$ & $\begin{array}{c}\text { Group 1A } \\
(\mathrm{n}=11)\end{array}$ & $\begin{array}{c}\text { Group 1B } \\
(\mathrm{n}=5)\end{array}$ & $\begin{array}{c}\text { Group 2 } \\
(\mathrm{n}=9)\end{array}$ \\
\hline TIBI on admission & $2.95 \pm 0.35$ & $2.45 \pm 0.24$ & $2.06 \pm 0.52$ \\
F-test $(p$-value) & \multicolumn{2}{c}{$0.55(0.85)$} & $3.05 \pm 0.17$ \\
TIBI after 24 hours & $4.32 \pm 0.32$ & $4.05 \pm 0.21$ & \\
F-test $(p$-value) & \multicolumn{2}{c}{$5.23(0.013)^{*}$} \\
Sig. bet. grps. & $p 1=0.24, p 2<0.017^{*}, p 3=0.59$ & \\
\hline
\end{tabular}

In this study it was found that, the recanalization was significantly more common with early administration of rt-PA (Table 3).

Table (3): Relation between recanalization by (CTA and TCD) and the timing of rt-PA administration.

\begin{tabular}{|c|c|c|c|}
\hline & \multicolumn{2}{|c|}{ Group $1(n=16)$} & \multirow{2}{*}{$\begin{array}{c}\text { Group } 2 \\
(n=9)\end{array}$} \\
\hline & $\begin{array}{l}\text { Group 1A } \\
(\mathrm{n}=11)\end{array}$ & $\underset{(n=5)}{\text { Group } 1 B}$ & \\
\hline rt-PA $>3$ hours & $10(81.2 \%)$ & $3(60 \%)$ & $2(22.2 \%)$ \\
\hline rt-PA $<3$ hours & $1 \quad(18.8 \%)$ & $2(40 \%)$ & $7(77.8 \%)$ \\
\hline$\chi 2$ ( $p$-value) & \multicolumn{2}{|c|}{$6.08(0.004)^{*}$} & \\
\hline
\end{tabular}

By using linear regression analysis of different factors (rt-PA administration time, NIHSS scale, cardiac problems, hypertension, previous stroke and diabetes mellitus) predicting canalization after rt-PA administration, shows that earlier rt-PA timing 
of administration and lower NIHSS scale were significant predictors for successful recanalization (Table 4).

Table (4): Linear regression analysis of factors predicting canalization after rt-PA administration.

\begin{tabular}{llccll}
\hline $\begin{array}{l}\text { Significant } \\
\text { predictor variables }\end{array}$ & $t$ & $\begin{array}{c}p \text { - } \\
\text { value }\end{array}$ & $\begin{array}{c}\text { R square } \\
\text { (effect) }\end{array}$ & F & $\begin{array}{c}\text { Confidence } \\
\text { interval }\end{array}$ \\
\hline rt-PA timing & 4.41 & $0.001^{*}$ & $45 \%$ & 19.25 & $0.20-0.55$ \\
NIHSS scale & 3.001 & $0.007^{*}$ & $61 \%$ & 17.32 & $0.013-0.075$ \\
Cardiac problem & 2.96 & 0.17 & $72 \%$ & 18.25 & $0.07-0.44$ \\
Hypertension & 2.25 & 0.55 & $50 \%$ & 16.5 & $0.01-0.86$ \\
Previous stroke & 2.43 & 0.53 & $13 \%$ & 7.2 & $0.05-0.9$ \\
Diabetes mellitus & 0.06 & 0.95 & & & $-0.6-1.1$ \\
\hline
\end{tabular}

In this study we can conclude that the sensitivity of TCD compared to CT angiography for detection of recanalization after rt-PA is about $81 \%$ and the specificity about $100 \%$ (Table 5).

Table (5): Sensitivity and specificity of TCD compared to CTA.

\begin{tabular}{|c|c|c|c|c|c|}
\hline \multirow[b]{2}{*}{ TCD } & \multicolumn{2}{|c|}{ CTA } & \multirow[b]{2}{*}{ Total } & \multirow{2}{*}{$\begin{array}{l}\text { Sensi- } \\
\text { tivity }\end{array}$} & \multirow{2}{*}{$\begin{array}{l}\text { Speci- } \\
\text { ficity }\end{array}$} \\
\hline & $\begin{array}{l}\text { Recanalized } \\
\quad(n=16)\end{array}$ & $\begin{array}{l}\text { Failed } \\
(n=9)\end{array}$ & & & \\
\hline $\begin{array}{l}\text { - } \text { Recanalised } \\
(\mathrm{n}=13) \\
\cdot \text { Failed } \\
\text { recanalization } \\
(\mathrm{n}=12)\end{array}$ & $\begin{array}{l}13 \\
\text { True +ve } \\
3 \\
\text { false +ve }\end{array}$ & $\begin{array}{l}0 \\
\text { False -ve } \\
9 \\
\text { True-ve }\end{array}$ & $\begin{array}{l}13 \\
12\end{array}$ & $\begin{array}{l}13 / 16 * 100 \\
=81.25 \%\end{array}$ & $\begin{array}{l}9 / 9 * 100 \\
=100 \%\end{array}$ \\
\hline Total & 16 & 9 & 25 & & \\
\hline
\end{tabular}

The positive predictive value of TCD compared to the CT angiography for detection of recanalization after rt-PA is $100 \%$ and the negative predictive value is about $75 \%$ (Table 6 ).

Table (6): Positive predictive value and negative predictive value of TCD.

\begin{tabular}{|c|c|c|c|c|c|}
\hline \multirow{2}{*}{ TCD } & \multicolumn{2}{|c|}{ CTA } & \multirow{2}{*}{ Total } & \multirow{2}{*}{$\begin{array}{c}\text { Positive } \\
\text { predictive } \\
\text { value }\end{array}$} & \multirow{2}{*}{$\begin{array}{c}\text { Negative } \\
\text { predictive } \\
\text { value }\end{array}$} \\
\hline & $\begin{array}{c}\text { Canalized } \\
(\mathrm{n}=16)\end{array}$ & $\begin{array}{l}\text { Failed } \\
(\mathrm{n}=9)\end{array}$ & & & \\
\hline $\begin{array}{c}\text { - Improved } \\
(\mathrm{n}=13) \\
\cdot \text { Failed } \\
(\mathrm{n}=12)\end{array}$ & $\begin{array}{l}13 \\
\text { True +ve } \\
3 \\
\text { false +ve }\end{array}$ & $\begin{array}{l}0 \\
\text { False -ve } \\
9 \\
\text { True -ve }\end{array}$ & $\begin{array}{l}13 \\
12\end{array}$ & $\begin{array}{l}13 / 13 * 100 \\
=100 \%\end{array}$ & $\begin{array}{l}9 / 12 * 100 \\
=75 \%\end{array}$ \\
\hline Total & 16 & 9 & 25 & & \\
\hline
\end{tabular}

Cases:

Case (1): Male patient, aged 32 years old, employer, married with 2 offspring, he is not hypertensive $(110 / 70)$, nor diabetic $(\mathrm{RBS}=130 \mathrm{mg} / \mathrm{dl})$. Her weight was $75 \mathrm{~kg}$, presented at emergency room within $80 \mathrm{~min}$ of onset by hyperacute onset of right side weakness (grade 0 ) associated with aphasia.
Initial NIHSS was 14 , and he received IV alteplase total dose of $67.5 \mathrm{mg}$; a bolus dose of $6.8 \mathrm{mg}$ over $1 \mathrm{~min}$ and remaining $(61 \mathrm{mg})$ dose infusion over $1 \mathrm{~h}$ after application of inclusion and exclusion criteria ( $2 \mathrm{~h}$ from onset). NIHSS after 24 hours was 10. He was discovered later to have PFO.

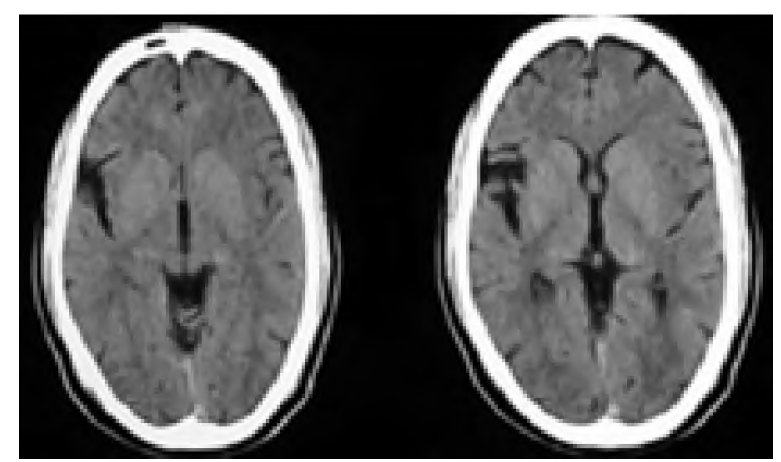

Fig. (1): Pre-treatment CT brain showed unremarkable changes.

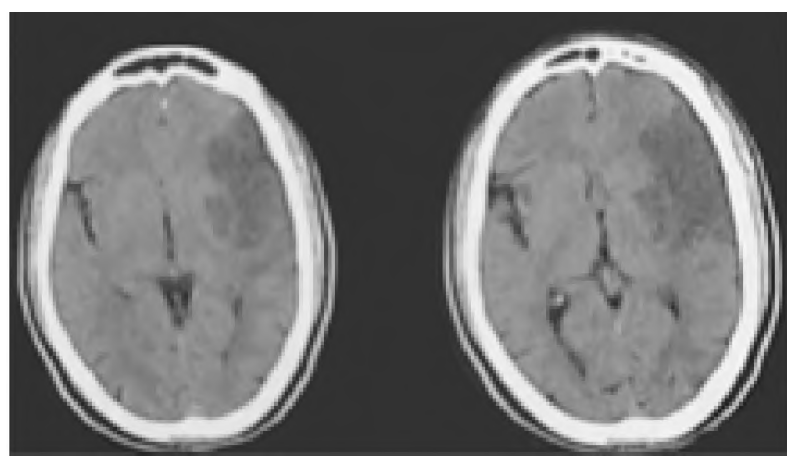

Fig. (2): 24h follow-up CT brain showed left perisylvian hypodensity.

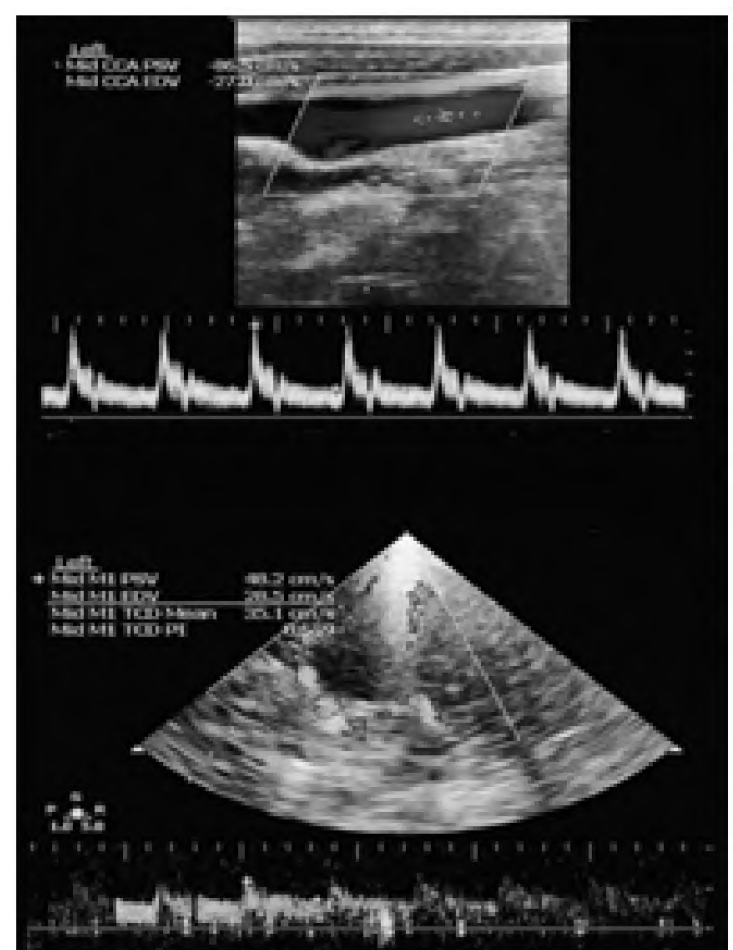

Fig. (3): TCD showing complete recanalization. 
Case (2): Male patient, worker, diabetic, hypertensive, 66 years old; presented by acute onset of left hemiplegia $($ Grade $=0)$ his pretreatment NIHSS was 14 . He was treated within $200 \mathrm{~min}$ with complete recanalization (grade 4 on TIBI). His initial NIHSS was 16, and he received IV alteplase total dose of $63 \mathrm{mg}$; a bolus dose of $6.3 \mathrm{mg}$ over $1 \mathrm{~min}$ and remaining $(57 \mathrm{mg})$ dose infusion over $1 \mathrm{~h}$ after application of inclusion and exclusion criteria $(2 \mathrm{~h}$ from onset). NIHSS after 24 hours was 6.

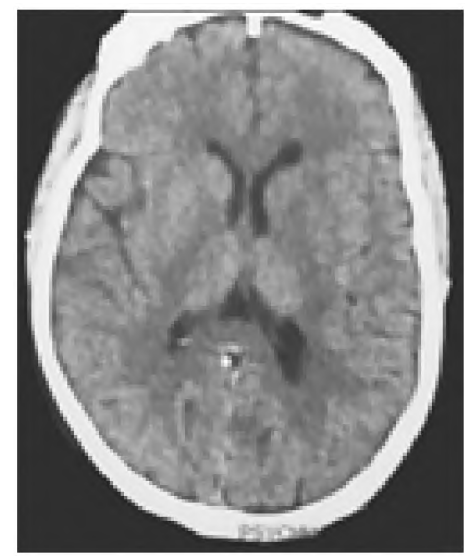

Fig. (4): Pre-treatment CT brain showed unremarkable changes.

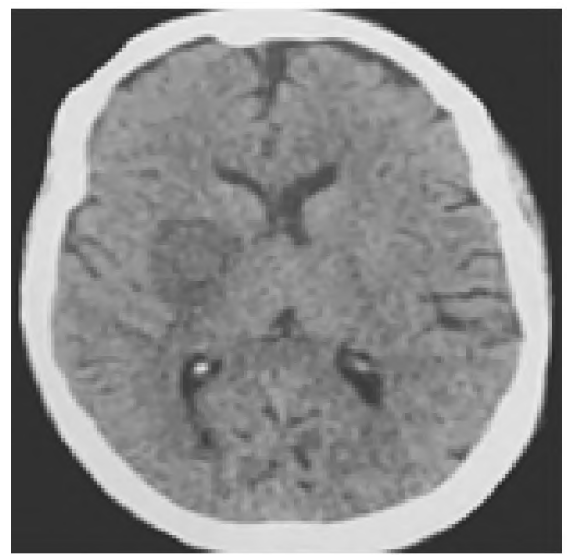

Fig. (5): CT brain after 24 hours: Hypodense area.

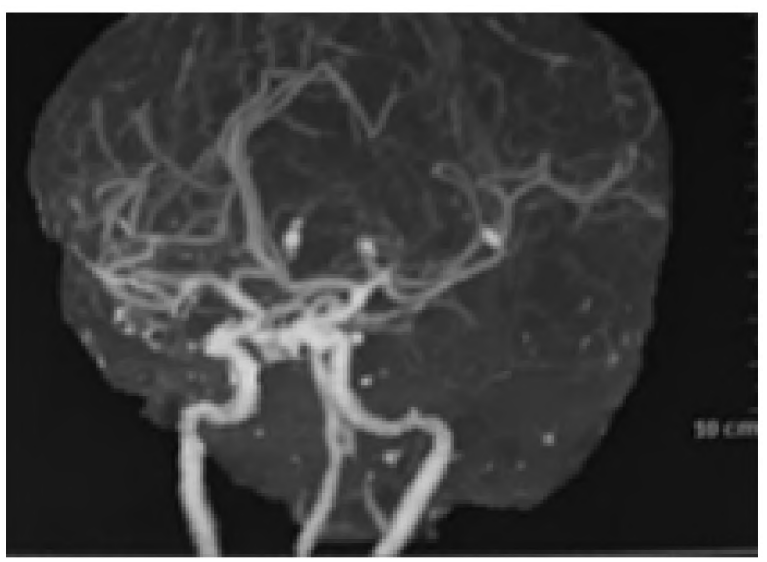

Fig. (6): CTA was normal.

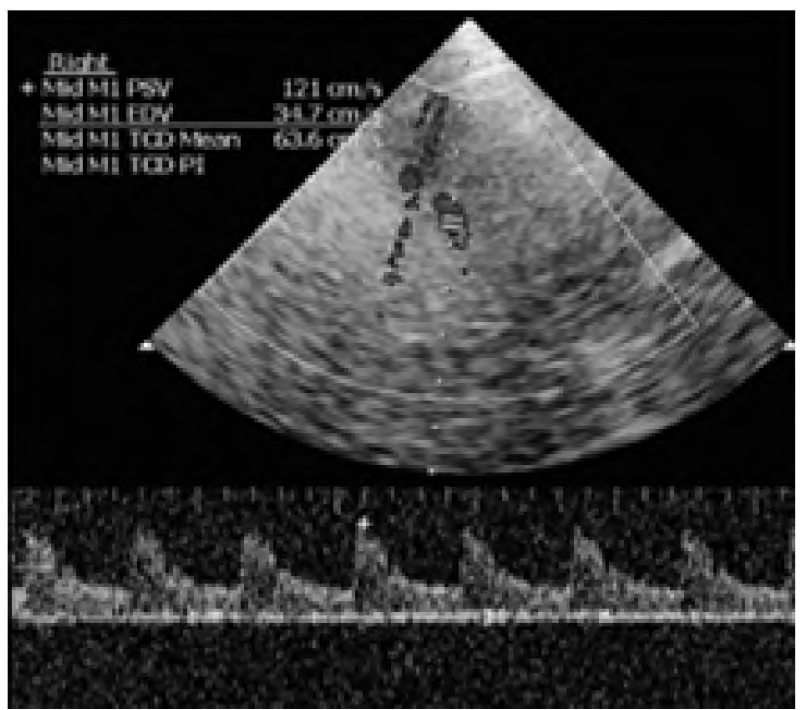

Fig. (7): TCD showing complete recanalization.

\section{Discussion}

This study reported that there is no significant difference between all groups regarding gender of the studied patients. There are multiple studies that evaluated the gender effect among intravenous rtPA-treated patients. None of these studies supported a gender difference in favorable outcome, and one suggested an increased risk of mortality in men [8].

Regarding risk factors; this study reported that the most common risk factors of strokes were hypertension (80\%), smoking (52\%), AF (48\%), DM (44\%), dyslipidemia (40\%) and carotid atherosclerosis $(32 \%)$. DM and smoking were significantly more common in patients with failed recanalization. This can be explained by the study of (Hafez S et al., 2014) who reported that the severity of hyperglycemia seems to be important for the neuronal injury as mild elevations do not increase the infarct size. However, the vasculature is more susceptible to even small elevations in blood glucose which mediate greater edema leading to poor outcomes in hyperglycemic ischemic brain injury. This study also reported that AF was significantly higher among patients with successful recanalization and this can be explained by younger age and better cerebral circulation in cardiac patients allowing better recanalization results [9].

There was significant difference in NIHSS score after 24 hours indicating that the recanalization was associated with significant improvement in stroke severity. Recanalization is associated with clinical improvement as patients who recanalized had lower NIHSS score on presentation ( $p=0.01$ ) 
and this comes in accordance with the study of (Erik Tandberg Askevold et al., 2006) who reported that high NIHSS score, high serum glucose, and higher number of risk factors indicate a reduced probability for recanalization [10].

According to this study, higher pretreatment ASPECT-scores are associated with a greater chance of complete recanalization and favorable long-term outcome in tPA-treated patients with acute MCA occlusion which was approved by the study of (Georgios Tsivgoulis et al., 2007) [11]

Regarding TIBI score after 24 hours, there was significant improvement as in group $2(3.55+1.17)$ and Group 1A (4.05+0.21) and in Group 1B (4.32 +0.32 ) denoting TIBI scale (by TCD) was significantly associated with initial stroke severity and clinical recovery. A flow-grade improvement correlated with clinical improvement which was approved by the study of (Demchuk AM et al., 2001) who reported pre-tPA NIHSS scores were higher in patients with TIBI grade 0 than TIBI grade 4 or 5 flow [12].

This study revealed that recanalization was significantly higher with early administration of rt-PA as $81.1 \%$ of Group 1A (recanalization with clinical improvement were administrated rt-PA in the first 3 hours of onset. While $77.8 \%$ of Group 2 (failed recanalization) were administrated rt-PA after 3 hours of onset. These results were similar to those reported by (Christou I et al., 2000) who reported that complete recanalization occurred in $12(30 \%)$ patients and partial recanalization occurred in $16(40 \%)$ patients (maximum observation time 360 minutes). Recanalization occurred within 60 minutes of tPA bolus in $75 \%$ of patients who recanalized [13]

When comparing mean values of NHISS scores according to time of administration in this study, there was a statically significant difference. This came in agreement with other studies as reported by (Hsu, et al., 2009) who concluded that better outcomes and more NIHSS reduction occurred with thrombolysis infusion within 90 minutes from the onset [14]

According to this study, TCD demonstrated 12 intracranial occlusions and CTA 13. There were 13 false positives and 1 false-negative diagnoses with TCD. TCD had a sensitivity of $81.25 \%$, and specificity of $100 \%$ for detecting an arterial occlusion in the middle cerebral artery. These results were in correlation with the study of (Alejandro $\mathrm{M}$ et al., 2009) who included 100 patients. TCD demonstrated 34 intracranial occlusions and CTA
33. There were 6 false positive and 4 false negative diagnoses with TCD. TCD in their had a sensitivity $95.6 \%$, and specificity $96.2 \%$ for detecting an arterial occlusion in the middle cerebral artery. In other words, they concluded that TCD is valid compared with CT angiography for the diagnosis of arterial occlusions in patients with acute ischemic stroke, especially in middle cerebral artery obstructions [15]

These findings were similar to those obtained by (Demchuk et al., 2000) who studied the reliability of single-gated TCD in intracranial occlusions, and (Tsivgoulis et al., 2007)who demonstrated the accuracy of intracranial ultrasound compared with CTA showing a high sensitivity and specificity of TCD in detecting alterations on any artery, especially MCA. Similar results had been obtained previously by (Ley-Pozo et al., 1990) and (Camerlingo et al., 1993) in anterior circulation artery occlusions.

\section{Limitations:}

Limited number of the studied patients was the main limitation of this study. Also, the study did not include other blood vessels of the brain like anterior cerebral artery.

\section{Conclusion:}

Intravenous rt-PA is a safe and effective treatment for acute ischemic stroke. Administration of intravenous rt-PA is associated with better recanalization rates among younger patients. Smoking and DM are significant predictors of poor recanalization after IV rt-PA while cardiac problems are associated with successful recanalization. Earlier administration of rt-PA, lower NIHSS on admission and distal MCA occlusion are significant predictors of successful recanalization. TCD is easy, fast and feasible tool to assess the occluded vessel before rt-PA with near results to CTA.

\section{Acknowledgments:}

This study was carried out without funding. We thank all the patients and/or their relatives who shared in the study.

\section{Conflicts of interest:}

No conflicts of interest declared.

\section{Authors' contributions:}

All authors had equal role in design, work, statistical analysis and manuscript writing.

\section{References}

1- THRIFT A.G., THAYABARANATHAN T.1., HOWARD G., HOWARD V.J., ROTHWELL P.M., FEIGIN V.L., 
NORRVING B., DONNAN G.A. and CADILHAC D.A.: Global stroke statistics. (Int. J. Stroke, Jan., 12 (1): 1332), 2017

2- ROTHWELL P.M.: Critical appraisal of the design and reporting of studies of imaging of acute stroke: The Lancet, Feb. 20; 385 (9968): 582-5, 2015.

3- CHARLES R.A.C., KUMAR P. and CLARKE M.: Cerebrovascular disease and stroke; Clinical Medicine, 5: 1163-73, 2008.

4- SRIKANTH V.K. and PHAN T.G.: Stroke: Clinical presentation, management and organization of services, Textbook of Geriatric Medicine and Gerontology; 7 th edition, 62: 484-97, 2010.

5- UYTTENBOOGAART M., VROOMEN P.C., STEWART R.E., De KEYSER J. and LUIJCKX G.J.: Safety of routine IV thrombolysis between 3 and $4.5 \mathrm{~h}$ after ischemic stroke. Journal of the neurological sciences, Mar. 15, 254 (1): 28-32, 2007.

6- DEMCHUK A.M., TANNE D., HILL M.D., KASNER S.E., HANSON S., GROND M., LEVINE S.R.: Predictors of good outcome after intravenous tPA for acute ischemic stroke. Neurology, Aug. 14, 57 (3): 474-80, 2001.

7- TANDBERG ASKEVOLD E., NAESS H. and THOMASSEN L.: Predictors for recanalization after intravenous thrombolysis in acute ischemic stroke Stroke Cerebrovasc Dis. Jan.-Feb., 16 (1): 21-4, 2007.

8- LYDEN P., BROTT T., TILLEY B., WELCH K.M., MAS CHA E.J., LEVINE S., et al.: Improved reliability of the NIH Stroke Scale using video training. NINDS TPA Stroke Study Group. Stroke, 25: 2220-6, 1994.

9- NEDELMANN M., STOLZ E., GERRIETS T., BAUMGARTNER R.W., MALFERRARI G., SEIDEL G. and KAPS M.: TCCS Consensus Group. Consensus recommendations for transcranial color-coded duplex sonography for the assessment of intracranial arteries in clinical trials on acute stroke. Stroke, Oct., 40 (10): 3238-44. doi: 10.1161 /STROKEAHA.109.555169, 2009.

10- PEXMAN J.W., BARBER P.A., HILL M.D., SEVICK R.J., DEMCHUK A.M., HUDON M.E., HU W.Y. and BUCHAN A.M.: Use of the Alberta Stroke Program Early CT Score (ASPECTS) for assessing CT scans in patients with acute stroke.American Journal of Neuroradiology. Sep. 1; 22 (8): 1534-429, 2001. Hafez S., Coucha M.,
Bruno A., Fagan S.C., Ergul A. Hyperglycemia, acute ischemic stroke, and thrombolytic therapy. Transl Stroke Res., Aug., 5 (4): 442-53, 2014.

11- TSIVGOULIS G., SAQQUR M., SHARMA V.K., LAO A.Y., HOOVER S.L. and ALEXANDROV A.V.: Association of Pretreatment ASPECTS Scores with tPA-Induced Arterial Recanalization in Acute Middle Cerebral Artery Occlusion. Journal of Neuroimaging, Jan. 1, 18 (1): 5661, 2008.

12- DEMCHUK A.M., TANNE D., HILL M.D., KASNER S.E., HANSON S., GROND M. and LEVINE S.R.: Predictors of good outcome after intravenous tPA for acute ischemic stroke. Neurology, Aug. 14, 57 (3): 474-80, 2001 .

13- CHRISTOU I., ALEXANDROV A.V., BURGIN W.S., WOJNER A.W., FELBERG R.A., MALKOFF M. and GROTTA J.C.: Timing of recanalization after tissue plasminogen activator therapy determined by transcranial Doppler correlates with clinical recovery from ischemic stroke. Stroke, Aug. 1, 31 (8): 1812-6, 2000.

14- HSU Y.C., SUNG S.F., ONG C.T., WU C.S. and SU Y.H.: Intravenous thrombolytic therapy for acute ischemic stroke: The experience of a community hospital. Acta Neurol. Taiwan, Mar., 18 (1): 14-20, 2009.

15- ALEJANDRO M. BRUNSER, M.D.; PABLO M. LAVADOS, M.D.; ARNOLD HOPPE, M.D.; JAVIERA LOPEZ, M.D.; MARCELA VALENZUELA, M.D. and RODRIGO RIVAS, M.D.: Accuracy of Transcranial Doppler Compared With CT Angiography in Diagnosing Arterial Obstructions in Acute Ischemic Strokes. (Stroke, 40: 203741), 2009.

16- LEY-POZO J. and RINGELSTEIN E.B.: Noninvasive detection of occlusive disease of the carotid siphon and middle cerebral artery. Ann. Neurol., 28: 640-4, 1990.

17-CAMERLINGO M., CASTO L., CENSORI B., FERRARO B., GAZZANIGA G.C. and MAMOLI A.: Transcranial Doppler in acute ischemic stroke of the middle cerebral artery territories. Acta Neurol. Scand., 88: 108-11, 1993.

18- ELENA MESEGUER, M.D.; PHILIPPA C. LAVALLÉE, M.D.; MIKAEL MAZIGHI, M.D., Ph.D.; JULIEN LABREUCHE, B.Sc.; LUCIE CABREJO, M.D. and JEANMARC OLIVOT, M.D.: Yield of systematic transcranialdoppler in patients with transient ischemic attack. Annals of Neurology, Vol 68 Issue1 Pages 7-19, 2009. 


\section{عوامل التثبؤ الإكلينيكية والإشعاعية بعد إعادة الإستقناء

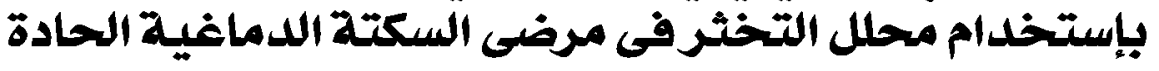

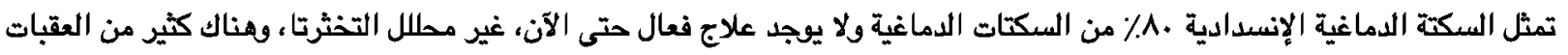

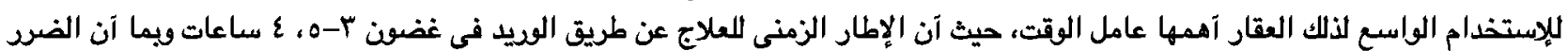

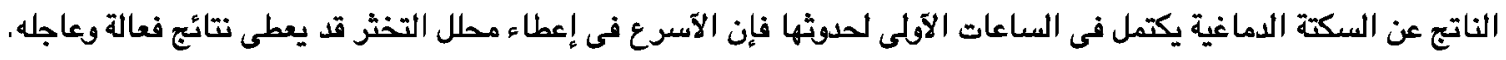

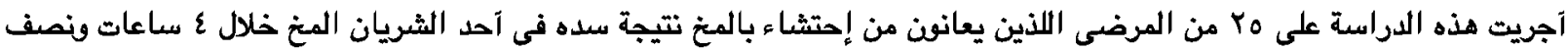

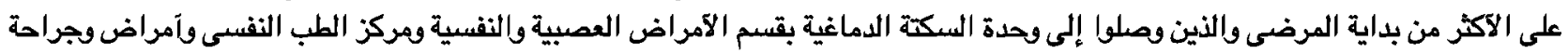

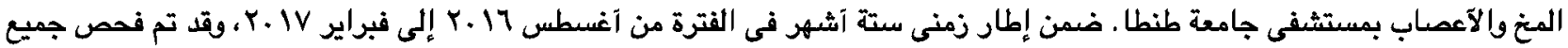

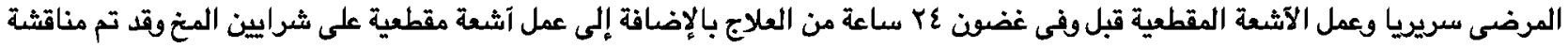

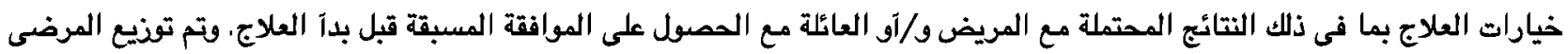
إلى مجموعتين:

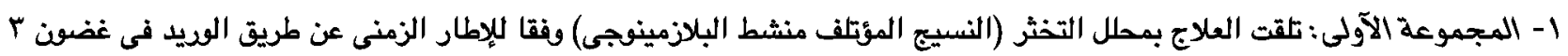

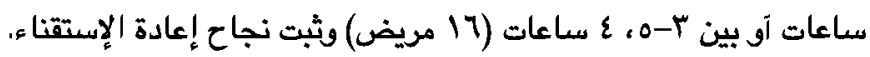
ץ- المجموعة الثانية: تكونت من تسعة مرضى، حيث لم تنجح عملية إعادة الإستقناء.

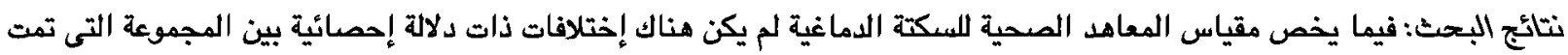

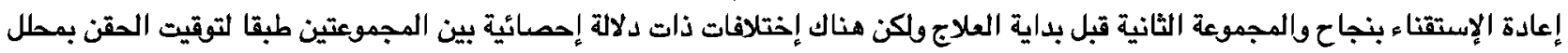

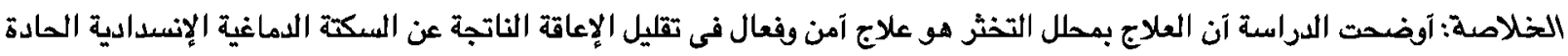

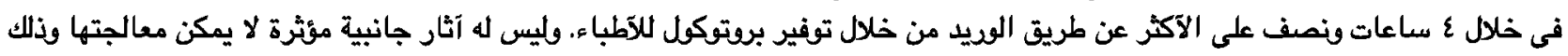
إذا تم آعطاه ضمن معايير البروتوكول المتبع. 